\title{
Enhanced space vector modulated scalar control of induction motor
}

Ramana Vasu R, George Fernandez S, Vijayakumar K

Faculty of Engineering and Technology, SRMIST, Chennai, India

\begin{tabular}{l}
\hline \hline Article Info \\
\hline Article history: \\
Received Jan 4, 2020 \\
Revised Mar 9, 2020 \\
Accepted Mar 15, 2020 \\
\hline
\end{tabular}

Keywords:

Indirect vector control

Induction motor

PI controller

Space vector modulated scalar

control

Speed control

\begin{abstract}
A conventional vector control of the asynchronous machine makes an analogy of an equivalent separately excited DC machine. It offers a decoupled control of torque and flux which is perpendicular to each other hence one vector is not interfered by other parameters. So, torque and speed control is achieved in an isolated manner even though they are closely interlinked. This is implemented by aligning the rotor flux with the direct axis of the synchronously rotating reference frame. PI controllers play a key role to achieve the desired topology of the VFD. Three controllers are used in the system, flux, speed and torque controller. Tuning of flux controller is quite simple, but in case of speed and torque, it became quite tricky because the output of the speed controller is the reference signal of torque controller. Moreover, there is no distinct method to tune the controllers in the vector control system. Still, the entire high-performance dynamic response of the machine depends on the perfect tuning of those controllers. From the above analysis, it is understood that system identification is essential to tune the PI controllers. But being an asynchronous machine, to obtain system transfer function in a decoupled manner is very difficult. To overcome this problem, the proposed model will be Conventional sine PWM modulated switching pulses are used to implement variable frequency drives for induction motor. Space vector modulated PWM switching pulse is used to fire IGBT. In the case of sine, PWM modulated switching, DC bus voltage utilization is 50\% whereas in space vector modulated inverter $57.73 \%$ DC Bus voltage utilization can be achieved.
\end{abstract}

This is an open access article under the CC BY-SA license.

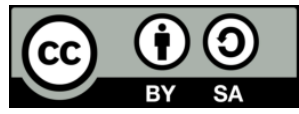

\section{Corresponding Author:}

George Fernandez S

Faculty of Engineering and Technology

SRMIST, Chennai, India

Email: George.electrix@gmail.com

\section{INTRODUCTION}

Nowadays, variable speed drives contribute essential power reserves and accurate response in manufacturing industries. Scalar controls are easy for execution and provides an exceptional response in steady-state. Still, the dynamics are slow because the transients are not controlled properly [1-3]. Vector control schemes have been invented with closed-loop feedback controls to achieve high accuracy dynamics. In the early of the 1970s, the principle of flux control was introduced and called field-oriented control or vector control for squirrel cage induction machines. The same was done for the synchronous machines later [4-8]. Scalar control ("V/Hz" approach) has its restrictions in terms of performance. It produces oscillations in the torque. So, it is becoming mandatory to find a control method to avoid the swings in the induction motors. By using the mathematical functions integrated microcontrollers, sensors, FPGA can be used for advanced control strategies for optimal operation. It has confirmed that $90 \%$ of connected motors are of the Squirrel cage type motors. Because of their reputation are robustness, fidelity, cheap, and efficiency. Various control systems are popular in the industry. 
AC drives is difficult for decoupled control. The rotor current in the squirrel cage motor is inaccessible. So, the control signals can be provided to only the stator current. Vice versa the torque equation is a non-linear function which is needed to find a linear control to achieve maximum torque generation [914]. However, it is challenging to achieve. But a better solution can be provided by the vector control method to overcome the challenge mentioned before. The existing system is designed vector control VFDs to operate the secondary sodium pump Motors rating of $2600 \mathrm{KW}$ with speed from zero rpm to $860 \mathrm{rpm} \&$ Primary sodium pump Motors rating of $3700 \mathrm{KW}$ with speed from zero rpm to $590 \mathrm{rpm}$ respectively [15-20]. The following disadvantages of existing vector control VFD system.

a) Require tachometer feedback from the motor. Which increases the price of the AC motor, and there is cost associated with mounting, wiring, and maintaining it. Since speed regulation is highly essential of our plant process requirement (Even one rpm also need to regulate during power operation). To achieve this speed regulation comprehensive circuit arrangement need to be incorporated.

b) Regeneration is more difficult with vector VFDs than traditional thyristor drives. Various components have all been used for regeneration with vector VFDs.

c) While the vector VFDs is used for dynamic braking applications, it requires different solutions. It might need dc braking to give functional dynamic braking. It is essential because the regulator on AC VFDs must be active to break the load.

d) Standard IM can be utilized with vector VFDs. Still, the high-performance inclinations of these VFDs can place more substantial requirements. Particular attention must be given to motors for optimized constant torque, high-overload duty over a wide speed range.

Hence, a new method is proposed to over the drawbacks which is presented in the next section.

\section{PROPOSED METHOD}

The following equations give a dynamic model of an induction motor in asynchronously rotating $\mathrm{d}-\mathrm{q}$ reference frame expressed in terms of state variables [21-23].

$$
\begin{aligned}
& \frac{d_{i s d}}{d_{t}}=-\left(\frac{R_{s}}{\sigma L_{s}}+\frac{1-\sigma}{\sigma \tau_{r}}\right) i s d+\omega_{e} i_{s d}+\omega_{e} i_{s d}+\frac{L_{m}}{\sigma L_{s} L_{r} \tau_{r}} \varphi_{r d}+\frac{L_{m} \omega_{r}}{\sigma L_{s} L_{r}} \varphi_{r q}+\frac{1}{\sigma L_{s}} V_{s d} \\
& \frac{d_{i s q}}{d t}=-\omega_{e} i_{s d}-\left(\frac{R_{s}}{\sigma L_{s}}+\frac{1-\sigma}{\sigma \tau_{r}}\right) i s d-\frac{L_{m} \omega_{r}}{\sigma L_{s} L_{r}} \varphi_{r d}+\frac{L_{m}}{\sigma L_{s} L_{r} \tau_{r}} \varphi_{r q}+\frac{1}{\sigma L_{s}} V_{s q} \\
& \frac{d \varphi_{r d}}{d t}=\frac{L_{m}}{\tau_{r}} i_{s d}-\frac{1}{\tau_{r}} \varphi_{r d}+\left(\omega_{e}-\omega_{r}\right) \varphi_{r q} \\
& \frac{d \varphi_{r q}}{d t}=\frac{L_{m}}{\tau_{r}} i_{s d}-\left(\omega_{e}-\omega_{r}\right) \varphi_{r d}-\frac{1}{\tau_{r}} \varphi_{r q} \\
& T_{e}=\frac{3 p}{4} \frac{L_{m}}{L_{r}}\left(\varphi_{r d} i_{s d}-\varphi_{r q} i_{s d}\right)
\end{aligned}
$$

Where,

$i_{s d}$ and $i s q$ stator current.

$V s d$ and $V s d$ stator voltage.

$\psi r d$ and $\psi r q$ rotor flux linkage.

$\sigma=1-L^{2} m / L_{r}$ is the leakage coefficient.

$L_{s}, L_{r}, L_{\omega}$ Mutual inductance of rotor and stator.

$R s$ and $R r$ resistance of rotor and stator.

$\omega_{e}$ is the synchronous speed

Reverse Park's transformation is used for obtaining the relation between stationary and synchronizing rotating reference.

$$
\left[\begin{array}{l}
\chi_{\mathrm{a}} \\
\chi_{\mathrm{b}} \\
\chi_{\mathrm{c}}
\end{array}\right]=\left[\begin{array}{cc}
\cos \left(\theta_{\mathrm{e}}\right) & -\sin \left(\theta_{\mathrm{e}}\right) \\
\cos \left(\theta_{\mathrm{e}}-\frac{2 \pi}{3}\right) & -\sin \left(\theta_{\mathrm{e}}-\frac{2 \pi}{3}\right) \\
\cos \left(\theta_{\mathrm{e}}+\frac{2 \pi}{3}\right) & -\sin \left(\theta_{\mathrm{e}}+\frac{2 \pi}{3}\right)
\end{array}\right]\left[\begin{array}{l}
\chi_{\mathrm{d}} \\
\chi_{\mathrm{q}}
\end{array}\right]
$$


The foremost goal of the scalar control is to manage the torque and the flux individually. if the current element is adapted or regulated in the flux direction while another current is set perpendicular to it, the machine will operate as a DC machine. The FOC is satisfies as follows.

$\varphi_{r q}=0, \varphi_{r d}=\varphi_{r}$

Then, the dynamic part (1) can be further simplified to,

$$
\begin{aligned}
& \frac{d_{i s d}}{d t}=-\left(\frac{R_{s}}{\sigma L_{s}}+\frac{1-\sigma}{\sigma \tau_{r}}\right) i s d+\omega_{e} i_{s q}+\omega_{e} i_{s d}+\frac{L_{m}}{\sigma L_{s} L_{r} \tau_{r}} \varphi_{r d}+\frac{L_{m} \omega_{r}}{\sigma L_{s} L_{r}} \varphi_{r q}+\frac{1}{\sigma L_{s}} V_{s d} \\
& \frac{d_{i s q}}{d t}=-\omega_{e} i_{s d}-\left(\frac{R_{s}}{\sigma L_{s}}+\frac{1-\sigma}{\sigma \tau_{r}}\right) i s q-\frac{L_{m} \omega_{r}}{\sigma L_{s} L_{r}} \varphi_{r d}+\frac{1}{\sigma L_{s}} V_{s q} \\
& \frac{d \varphi_{r d}}{d t}=\frac{L_{m}}{\tau_{r}} i s d-\frac{1}{\tau_{r}} \varphi_{r d} \\
& 0=\frac{L_{m}}{\tau_{r}} i_{s q}-\left(\omega_{e}-\omega_{r}\right) \varphi_{r d} \\
& T_{e}=\frac{3_{p}}{4} \frac{L_{m}}{L_{r}} \varphi_{r d} i_{s q}
\end{aligned}
$$

Therefore, torque (8) becomes equivalent to the DC machine as follows,

$$
T_{e}=\frac{3 p}{4} \frac{L_{m}}{L_{r}} \varphi_{r d} i_{s q}=K_{T} i_{s q}
$$

Where, $K_{T}$ is the torque constant and is expressed as given below:

$K_{T}=\frac{3 p}{4} \frac{L_{m}}{L_{r}} \varphi *_{r d}$ below:

Where $\varphi *_{r d}$ represents the rotor flux and the slip frequency $\omega_{s l}$ can be derived from (7) as given

$\omega_{s l}=\omega_{e}-\omega_{r}=\frac{L_{m}}{\tau_{r}} \frac{i_{s q}}{\varphi_{r d}}$

Hence (4) and (5) can be decoupled by following:

$$
\begin{aligned}
& V_{s d}^{*}=\left(K_{p}+K_{i} \frac{1}{s}\right)\left(i_{s d}^{*}-i_{s d}\right)-\omega_{e} \sigma L_{s} i_{s q}^{*} \\
& V_{s q}^{*}=\left(K_{p}+K_{i} \frac{1}{s}\right)\left(i_{s q}^{*}-i_{s d}\right)+\omega_{e} \sigma L_{s} i_{s d}^{*}+\omega_{e} \frac{L_{m}}{L_{r}} \varphi_{r d}
\end{aligned}
$$

The impedance will be changed if the frequency is increasing or decreasing. The constant flux in the stator can be provided as follows:

$V_{r m s}=4.44 K . N \cdot \lambda s . f$

Stable control technique (not affected by any feedback errors)

\subsection{Closed loop-V/F control model}

The induction motor dynamic simulation model is presented in Figure 1 and the closed loop control Simulink is presented in Figure 2. The principle of constant V/F speed control is to implement a changeable magnitude, and variable frequency voltage to the motor. Closed-loop V/F control using a VSI is given in the block diagram [24, 25]. 


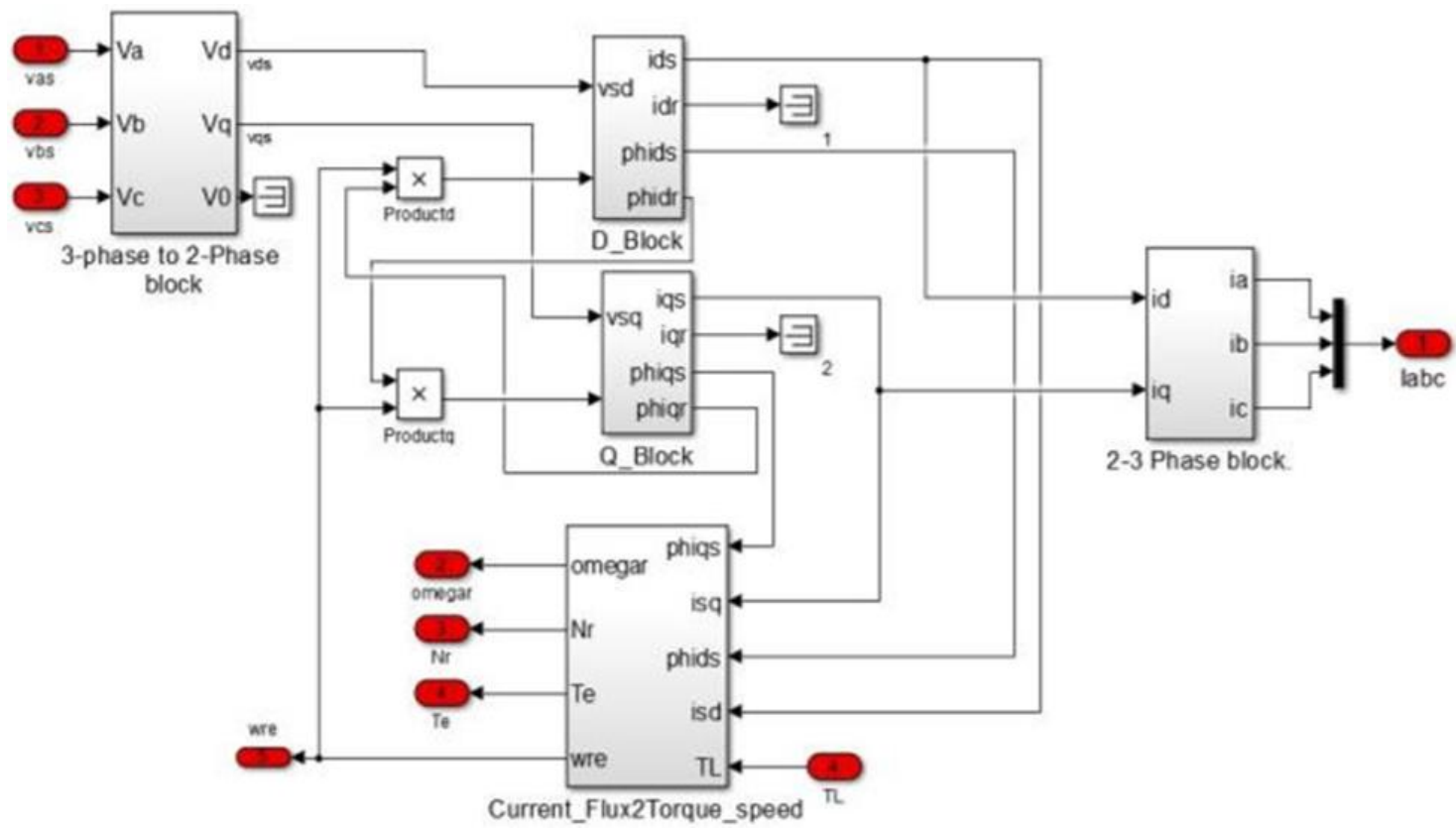

Figure 1. Induction motor dynamic model simulink circuit
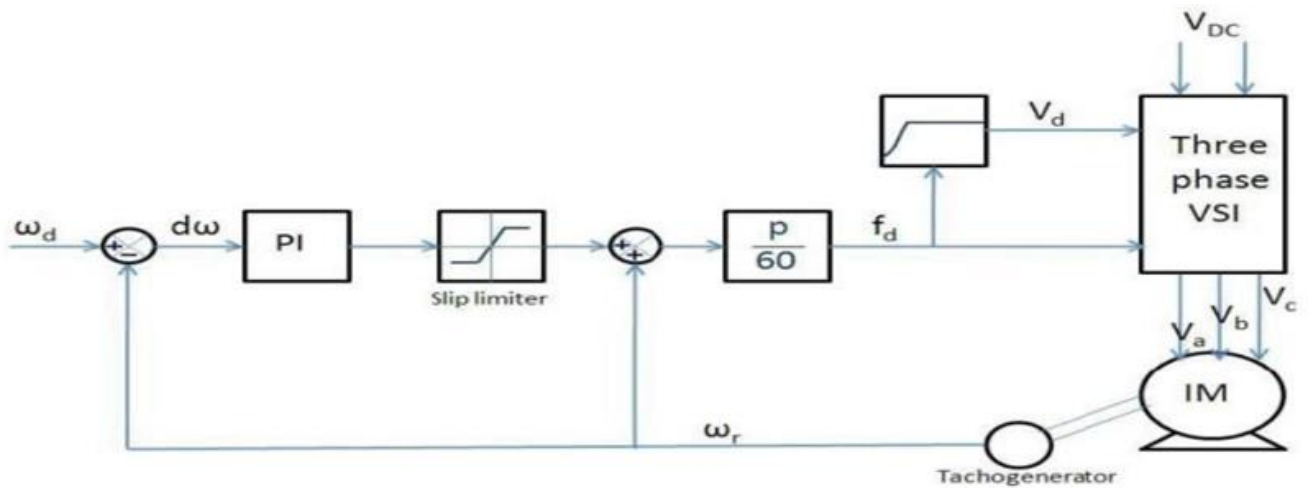

Figure 2. Closed-loop V/Hz constant control

\section{RESULTS AND DISCUSSION}

The response of speed torque and current are simulated and resulted are captured. Fluke 434 power quality analyzer is connected to the inverter $\mathrm{O} / \mathrm{P}$ to measure the power quality. Unfiltered voltage and current were captured and it was observed that at reduced frequency power factor is reduced. The machine was operated from zero to maximum speed to confirm the flux level. As the modulation index of the frequency converter is directly proportional to the voltage amplitude, so we can state that the RPM/f ratio is scaled to $\mathrm{v} / \mathrm{f}$ ratio which is constant and shown in the above Table 1.

At frequency $50.58 \mathrm{HZ}$ the power factor was $0.96 \mathrm{lag}$. While frequency coming down the power factor also decreasing and below $25 \mathrm{~Hz}$ the Pf was $0.76 \mathrm{lag}$ and during starting the power factor was $0.34 \mathrm{lag}$. Operating procedure of vfd is given. Hence, the $V-f$ relation is adequate, the motor speed response is also improved as shown in Figure 3. First, ensure all pre request are met (Tools\&tackles, manpower, etc.). Energize the DC regulated power supply to the inverter. Switch on the single-phase power supply (240V AC) to the isolated power supply unit. Keep potentiometer to minimum position. Ensure Motor shaft feedback given to microcontroller. The torque is normalized with respect to the nominal torque value. The actual torque response for a given frequency along with the voltage calculated to the $V / f$ relation is shown in Figure 4. 
Table 1. Motor characteristics at different speed

\begin{tabular}{cccc}
\hline Sl.No. & RPM & Power Frequency $(\mathrm{Hz})$ & RPM/f Ratio \\
\hline 1 & 720.74 & 50.5 & 14.26 \\
2 & 607.09 & 42.03 & 14.44 \\
3 & 496 & 36.3 & 13.66 \\
\hline
\end{tabular}

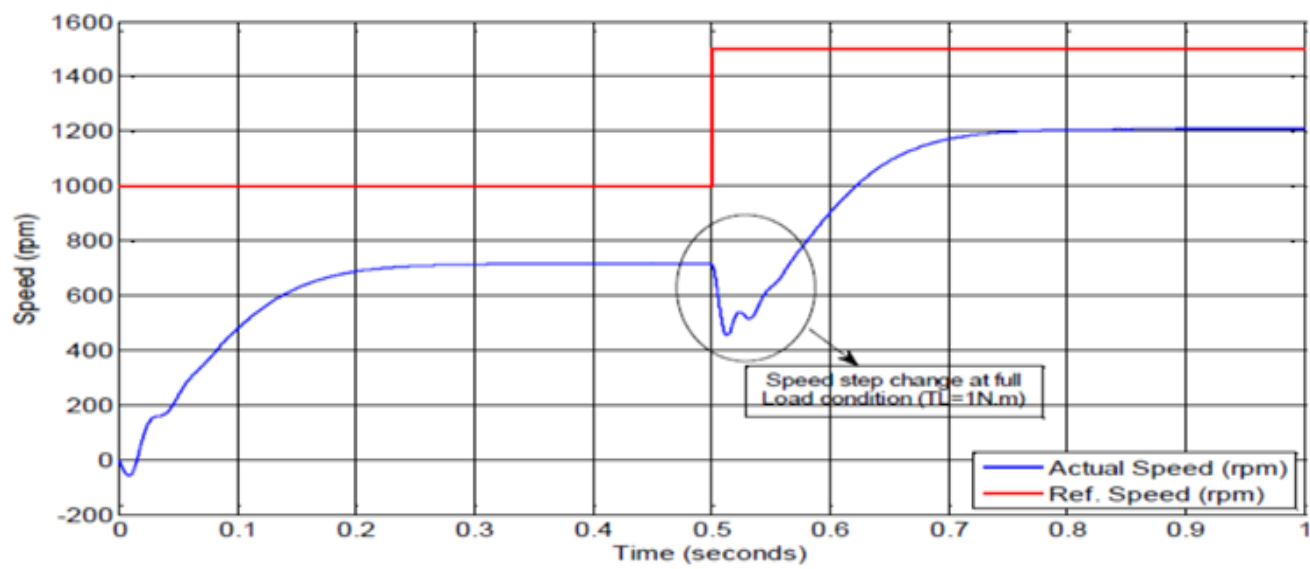

Figure 3. Speed response

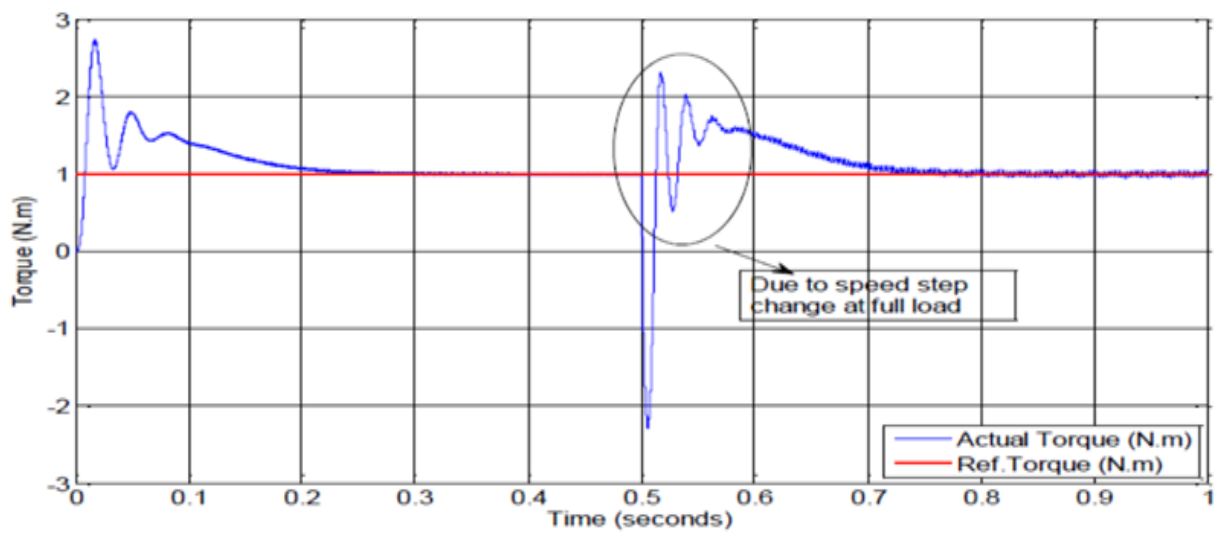

Figure 4. Torque response

Through the starting of the motor and load torque increase. Speed increases while motor torque is greater than load torque. After having reached its maximum value, motor torque decreases as speed keeps increasing and the obtained current response is shown in Figure 5(a) and Figure 5(b). The Hardware of VFD Controller is given in Figure 6. Switch on the power supply to micro controller. Release the loading unit to zero value (N-M). Slowly increase the potentiometer position and observe motor start rotating. Measure the Motor speed conditionally with taco generator. Note the various parameters in power quality analyzer (frequency, power factor, THD, voltage current\&etc). Increase the potentiometer to maximum position and note down the motor attains full speed. Observe any abnormalities in the controller circuit and motor running smoothly. Apply the break on the motor in step and note down the motor speed and current with torque value of $10 \mathrm{~N}-\mathrm{M}$. Observe the motor current, voltage, frequency, speed, etc. Allow the drive to operate 10 minutes and observe drive and motor is operating normal. Reduce the potentiometer in step and note down the all the parameters (speed, frequency, power factor, voltage, current etc). 


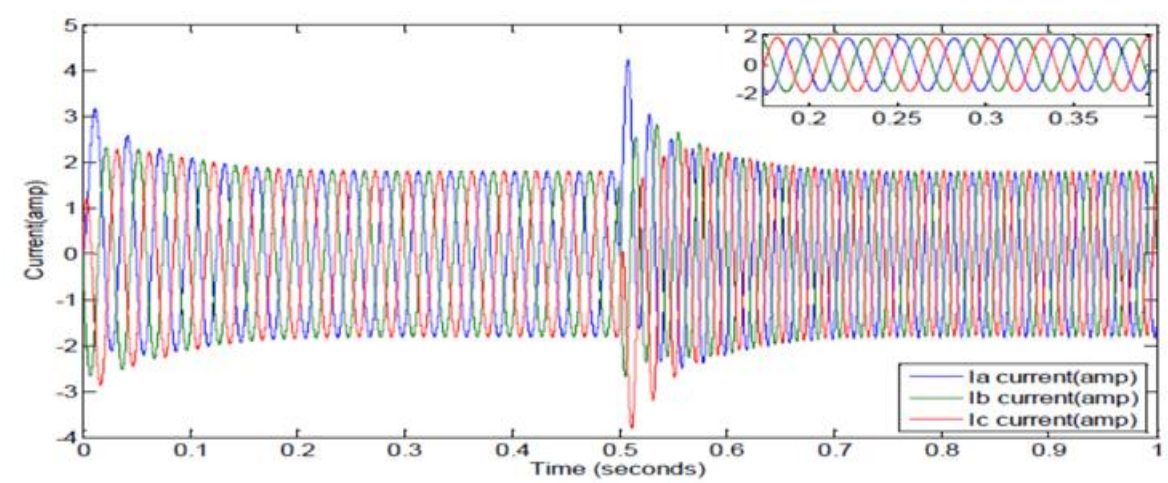

(a)

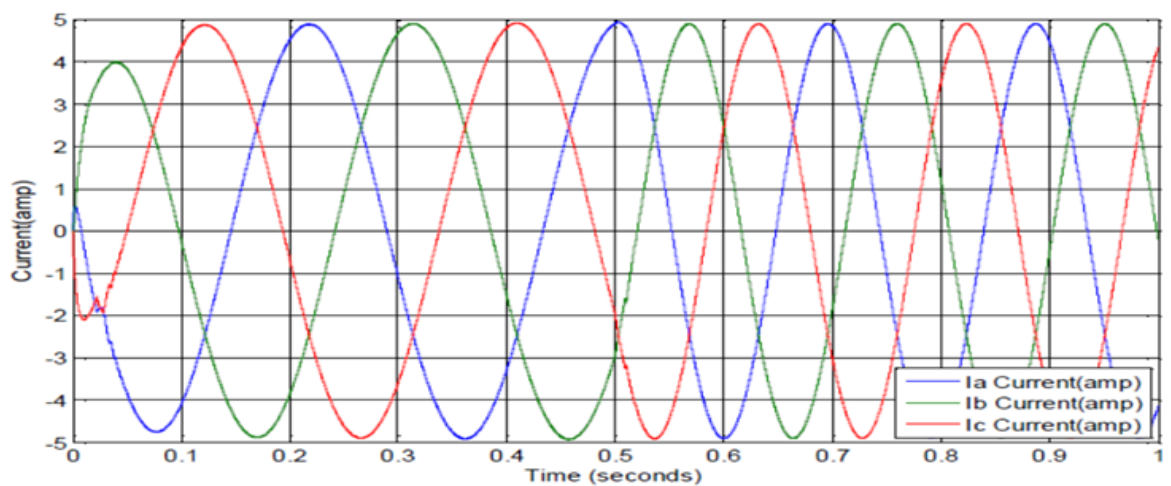

(b)

Figure 5. Current response

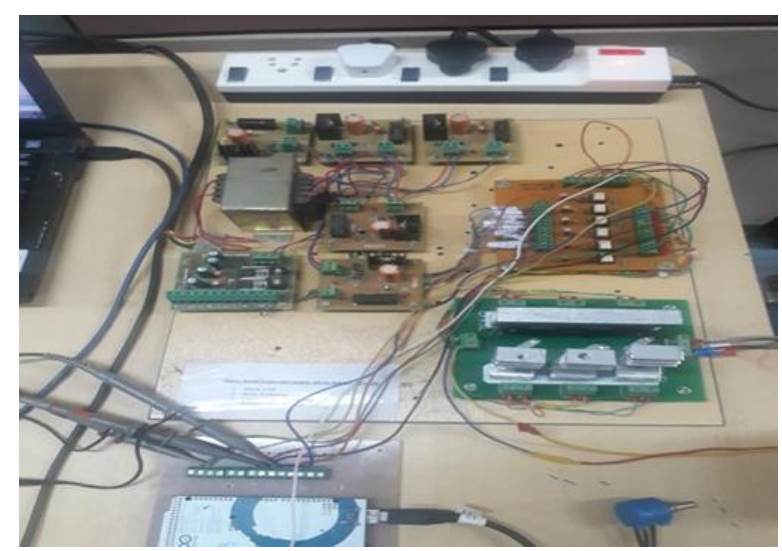

Figure 6. Hardware setup of VFD controller

Bring the potentiometer zero position and ensure motor comes to rest. Switch off the drive controller power supply, Inverter power supply, revert back the system to normal.

\section{CONCLUSION}

The performance of the scalar mode controller is compared with that of the classical PI controller. The simulation results show that the designed scalar mode controller realizes an excellent dynamic behaviour of the motor during sudden variations with a fast settling time. It shows that the recommended control plan functions relatively prominent. Finally, the speed tracking objective is obtained following changes in the load torque and other parameters. The predicted speed includes ripples due to variation of current and speed 
sampling times. Based on the experienced and depth of knowledge gained by the simulation of field-orientated control variable frequency drive $\&$ hardware model for space vector modulated scalar control of induction motor for soft starting. It is proposed to develop the model free motor control method similar to soft start of induction machine applicable to sodium system cold trap blower motor $(160 \mathrm{KW}, 415 \mathrm{~V}, 1500$ rpm \& load current 300Amps). Which will drastically eliminate the effect of passive parameters changes in the machine in case of vector control the dynamic response derived from desire output which was in proposed mechanism, the entire control pulse derived from the user input.

\section{REFERENCES}

[1] Z. B. Duranay, H. Guldemir, "Selective harmonic eliminated V/f speed control of single-phase induction motor," IET Power Electronics, vol. 11, no. 3, pp. 477-483, 2017.

[2] M. Masiala, B.Vafakhah, A. Knght, J. Salmon, "Performance of PI and fuzzy logic speed control of field-oriented induction motor drive," CCECE, pp. 397-400, 2007.

[3] F. Barrero, A. Gonzalez, A. Torralba, E. Galvan, L. G. Franquelo, "Speed control of induction motors using a novel Fuzzy-sliding mode structure," IEEE Transaction on Fuzzy system, vol. 10, no. 3, pp. 383.

[4] H.F.Ho, K. W. E. Cheng, "position control of induction motor using indirect adaptive fuzzy sliding mode control," 2009 3rd International Conference on Power Electronics Systems and Applications, pp. 1-5, 2009.

[5] R. J. Wai, "Fuzzy sliding-mode control using adaptive tuning technique," IEEE Transaction on Industrial Electron., vol. 54, no.1, pp. 586-594, 2007.

[6] F. J. Lin, H. M. Su, and H. P. Chen, "Induction motor servo drive with adaptive rotor time- constant estimation," IEEE Transaction on Aerospace Electronic system, vol. 34, pp. 224-234, 1998.

[7] V. I. Utkin, "Sliding mode control design principle and application to electric drives," IEEE Transaction on Industrial Electronics, vol. 40, no. 1, pp. 23-36, 1993.

[8] A. Derdiyok, "Speed-sensorless control of induction motor using continuous control approach of sliding-mode and flux observer," IEEE Trans. on Industrial Electronics, vol. 52, no. 4, pp. 140-148, 2005.

[9] A. Abbondanti, M. B. Brennen, "Variable speed induction motor drives use electronic slip calculator based on motor voltages and currents," IEEE Trans. Industrial Applications, vol. 11, pp. 483-488, 1975.

[10] C. C. Chan, H. Q. Wang, "New scheme of sliding mode control for high performance induction motor drives," IEE Proc. on Electric Power Applications, vol. 143, no. 3, pp. 177-185, 1996.

[11] C. Lascu, I. Boldea and F. Blaabjerg, "Direct torque control of sensorless induction motor drives: a sliding-mode approach," in IEEE Transactions on Industry Applications, vol. 40, no. 2, pp. 582-590, 2004. doi: 10.1109/TIA.2004.824441.

[12] Chan, C. C., and H. Q. Wang, "New scheme of sliding mode control for high performance induction motor drives," IEE Proc. on Electric Power Applications, vol. 143, no. 3, pp 177-185, 1996.

[13] Chan C. C., Leung W. S. and C. W. Nag, "Adaptive decoupling control of induction motor drives," IEEE Transaction on Industrial Electronics, vol. 35, no. 1, pp.41-47, 2010.

[14] D. Sattianadan, G. F Savari, “Techno Economic Evaluation of a Hybrid energy system," International Journal of Recent Technology and Engineering, vol. 8, no. 2 S11, pp. 2575-2579, 2019.

[15] Palanisamy R, Vijayakumar K, "Common Mode Voltage Reduction Using 3D-SVPWM for 3-level CI-NPC Inverter with Hybrid Energy System,” Electric Power Components and Systems, 2018.

[16] K. Selvakumar, K. Vijayakumar, D. Karthikeyan, D. Selvabharathi, V. Kubendran, "Hysteresis control 3-level SINPC inverter with wind energy system," International Journal of Power Electronics and Drive System (IJPEDS), vol. 8 , no. $4,2017$.

[17] K. Vijayakumar, Shurya Misra, K. Selvakumar, D. Karthikeyan, "A closed loop current control of PV-wind hybrid source fed grid connected transformerless diode clamped-multi level inverter," International Review On Modelling And Simulations, vol. 8, no. 4, 2015.

[18] Palanisamy R., Selvakumar K., and Karthikeyan D., "Simulation of matrix converter for induction motor," at ICETS'17, Muthyammal College Of Engg, Namakkal, 30th \& 31 $1^{\text {st }}, 2017$.

[19] D. Sattianadan "Uninterrupted supply to BLDC motor using PV and grid," International Journal of Recent Technology and Engineering, vol. 8, no. 2 S11, pp. 3357-3362, 2019.

[20] M. A. J Sathik, et al., "A New Generalized Multilevel Converter Topology with Reduced Voltage on Switches, Power losses and Components," IEEE Journal of Emerging Selected Topics in Power Electronics, vol. 7, no. 2, pp. 1094-1106, 2019.

[21] P. Suresh, S. George Fernandez, "Reduction of transients in switches using embedded machine learning," International Journal of Power Electronics and Drive Systems, vol. 11, no. 1, pp. 235-241, 2020.

[22] D. Sattianadan, V. Kalyanasundaram, S. Vidyasagar, Deepak Kumar NayakRoopamJha, "Maximum Power Point Tracking for a Grid Connected Photovoltaic System Using Sliding Mode Control," International Journal of Power Electronics and Drive System (IJPEDS), vol. 8, no. 4, pp. 1785-1792, 2017.

[23] Vidyasagar S., "Energy management system connected for microgrid using fuzzy logic algorithm," International Journal of Recent Technology and Engineering, vol. 8, no. 2 S11, pp. 2522-2527, 2019.

[24] K. Vijayakumar and K. Saravanan, "Fuzzy logic based duty cycle estimation for Maximum Power Point Tracking in Photovoltaic Systems," Journal of Advanced Research in Dynamical and Control Systems, vol. 7, no. 12, 2018.

[25] R. Bharti, M. Kumar and B. M. Prasad, "V/F Control of Three Phase Induction Motor," International Conference on Vision Towards Emerging Trends in Communication and Networking (ViTECoN), Vellore, India, pp. 1-4, 2019. 